\title{
Palliative Sedation in Children and Adolescents: the Repercussion in the Family
}

\begin{abstract}
Cícero Roberto Pinheiro Grangeiro Júnior 1,2,3 , João Vitor Cândido Pimentel1,2,3, Emídio Antonio de Araújo Neto ${ }^{4}$, Regiane Teixeira Silveira ${ }^{4}$, Maria Fernanda dos Santos ${ }^{4}$, Maria do Socorro Martins Cardoso Novais ${ }^{4}$, Janaina Batista Pereira ${ }^{4}$, Florido Sampaio das Neves Peixoto ${ }^{4}$, Hellen Lucia Luz Caldas Lins ${ }^{4,5}$, Modesto Leite Rolim Neto1,2,3,4, Patrícia Gonçalves Pinheiro 5
\end{abstract}

\section{Abstract}

Background: Estimative demonstrate about $6 \%$ of the 20 million people needing palliative care at the end of their life are less than 15 years old. Despite of that, researchers reported several areas of parent dissatisfaction with care including confusing, inadequate, or uncaring communications with clinicians regarding treatment or prognosis of the child's end of life.

Objective: Here we show that about $90 \%$ of the families that have a child or an adolescent passing through a situation that needs Palliative Sedation think that this process was necessary to relieve the suffering of the patient.

Results: In several reports, parents of terminally ill children describe their perceptions of uncaring and insufficient communication from health care professionals and link that communication with their own lingering regrets and emotional distress.

Conclusion: There is the necessity to better capacity the supportive and care team, in order to diminish guilty and grieve feelings, and to provide courses to the care team that can develop the communication process among them and the family.
1 Federal University of Cariri, Divine Savior Street, 284, Center, Barbalha, Ceará, Brazil.

2 Scientific Writing Lab (LABESCI) -Federal University of Cariri (UFCA), Barbalha, Ceará, Brazil.

3 Suicidology Research group -Federal University of Ceará (UFC)/National Council for Scientific and Technological Development (CNPq).

4 Post Graduation Program in Health Science, Faculty of Medicine of $A B C$, Santo André, São Paulo, Brazil.

5 Faculty of Medicine, Estacio -FMJ, Juazeiro do Norte, Ceará, Brazil.

\section{Contact information:}

Modesto Leite Rolim Neto.

ほ modestorolim@yahoo.com.br

\section{Keywords}

Palliative Sedation; Children; Adolescents; Relatives; Experience. 
It is known that palliative sedation (PS) is frequently used in end-of-life care: the incidence estimates of the use of sedatives prior to death range from $15 \%$ up to more than $60 \%$ of patients [1-5], and although it is used in all settings where patients die, its use occurs often in hospitals and for patients with cancer [6-10], once these patients usually suffer from dyspnea, pain and terminal restlessness $[1,2,5,11,12]$.

About $6 \%$ of the 20 million people needing palliative care at the end of their life are under 15 years old [13]. Despite the narrow definition for children is from 1 to 9 years of age, in this paper the term children is used in a larger sense to comprise neonates, infants and often adolescents.

Besides of being a process only used, nowadays, following previous made guidelines [14], there is still a difficult to establish how, when and by whom a symptom is defined as refractory, as symptom that advocates the use of palliative sedation, especially in case of children, in which there are difficulties in communication and in giving them due autonomy, leaving only to the family the discussions of the processes [15].

In many studies reviewed, parental perspective was taken into account for decision making [16, 17, 18] focusing on certainty that the child cannot be cured, perception of suffering and the child quality of life [15]. However, parents and physicians did not always agree on the way decisions for children with cancer were made and parents were often involved only after the physicians had made their decisions [19]. Pousset et al. [20] showed that, although parents consented to continuous and deep sedation in most cases (77.8\%) and requested sedation in $16.7 \%$ of them, in $16.7 \%$ of the cases, there was no request or consent from the parents. However, two third of the relatives think that they were responsible for the decision of doing the palliative sedation in University Hospitals of Geneva [21] and a series of interviews with relatives of patients showed that most of them liked their direct decision to begin the palliative sedation [22], instead of the care group.

Despite of this, the decision making in adolescents is more complex because they are able to understand and take part in the process, while at the same time they may have strong feelings about continued treatment [23]. A study made with children in end-of-life (EOL) showed that patients were often involved in EOL decisions when they were 12 or more years old. [20]

A Boston study showed that among decisionmaking factors, parents rated the quality of life, likelihood of improvement, and pain as most important. [24] There are much influences that can direct treatment decision-making by patients, family members, and clinicians, like personal, family, community and cultural values and beliefs, customs, actions, and communications that evolve and accumulate during life experiences of a person. [6, 25-30] These influences can be the source of both agreement and disagreement among these decision-makers. [30-34] Also, the place of dying can be included in these factors, once, for example, decisions at home were usually more often discussed with patients [35]. Finally, Dussel and colleagues [36], in their study, found that more than $10 \%$ of parents had considered hastening death if their child was in intolerable pain.

The negative effects of poor communication and insensitive delivery of bad news on the parents' long-term emotional and psychological well-being are well documented [37]. Communication with parents about their child's end of life may be difficult or fail altogether, even when skilled palliative care clinicians are involved. [38] Contro et al [39] reported several areas of parent dissatisfaction with care including confusing, inadequate, or uncaring communications with clinicians regarding treatment or prognosis of the child's end of life. [30]

Still, there is the importance to explain them that the belief of death anticipation with palliative sedation is wrong. According to recent studies of 
Sykes \& Thorn [40] and Maltoni et al. [41] and Mercadante et al. [42], there are evidences that the provided administration of sedatives does not shorten the life. Therefore, those concerns presented were caused, in general, by the low level of information received about the process, fact that lead to high levels of dissatisfaction and distress by the relatives [22]. Without adequate information, parents have great difficulty to arrive at the point of transitioning, a necessary precursor of End-OfLife decision making [16, 17, 18].

In several reports, parents of terminally ill children describe their perceptions of uncaring and insufficient communication from health care professionals and link that communication with their own lingering regrets and emotional distress. [39, 43-46] Giving clear information about what to expect in the end-of-life period, communicating bad news in a sensitive and caring manner, communicating directly with the child, when appropriate, and preparing the parent for the circumstances likely to arise near the time of the child's death were associated with higher parental ratings of physician care. [47, 48]

About $90 \%$ of the families that have a relative passing through a situation that needs palliative sedation think that the PS was necessary to relieve the suffering of the patient [21]. Moreover, the option for the palliative sedation is chosen not only to relieve the patient's pain, but also to relief the family suffering [22], once the palliative sedation can emotionally affect the family of the patient in palliative care [49]. Relatives must handle both their own sorrow and that of the dying person, in addition to solving a multitude of practical problems. [50] It was hypothesized that parent's cultural differences can lead to higher or lower levels of anxiety, which can affect the whole treatment; when there is much anxiety, the pain treatment can fail because the parents can not comfort their children sufficiently. [51]

During the start of continuous palliative sedation, despite the dying family member suffering less than before, the relatives may be confronted with thoughts and feelings about the decision for continuous palliative sedation, and questions and concerns about it will be expressed [49]. Relatives usually express a various of bad feelings caused, in general, by reasons linked to the process of the sedation, like being awake for several days, the inability to interact with the patient, a longer duration of the sedation and concerns about a possibly hastened death and difficulties with information [52], and, as a part of "anticipatory grief", families of children with complex chronic conditions or lifethreatening illness may have already thought about the child's funeral and plans before the death. [37]

Health care to the patient stops with the patient's death, but the suffering of the family and other loved ones goes on and so should bereavement care [49]. Psychologic and physical distress, reported as depression, feelings of grief, guilt, or anxiety, insomnia, headaches, and musculoskeletal pain, are common among parents and siblings after the death of a child. [43]

In case of children and adolescents, the death of a sibling is more severe because it occurs when they are "forming their view of the world and their own identity." Emotional responses may include sadness, fear, anger, rejection, pain, grief, confusion, guilt about being alive, jealous of the deceased getting the parents' attention and loneliness as well as more complicated feelings. [37, 53] Such situations should be anticipated and parents should be encouraged to deal sensitively with these concerns [49].

For the parents, in other hand, the memory of the symptomatology of the dying child may linger for a long time in their memory and can drastically affect the bereavement process. [54, 55] Also, the child's death is one of the most intense and painful events that a parent can experience, and parental grief is more intense and longer lasting than other types of grief and is associated with increased risk of psychological and physical illness. [37, 56-61] However, there are studies documenting that, af- 
ter death, parents have found meaning and solace in the opportunity to donate their children's organs. [62-64]

When children die, their parents and siblings may require extensive counseling $[23,65]$. To support the family of the dying or dead child, the palliative care or other support group must take place, like community religious figures and important members of their support system. [66]

Some authors emphasize the benefits of the meeting among care staff and the parents, perhaps affecting their own emotional health for years to come $[23,67]$, once the clinicians, usually previously unknown to the family, were quickly drawn into the family's inner circle of support and nurses were considered more involved during the death process than other family members or friends. 24 This meeting would give the health care team an opportunity to answer questions (especially if there was an autopsy), check on the parents' or family's well-being, and give the parents or family members an opportunity to say a final goodbye to their favorite caregivers. [23]

Although there are gender differences in grieving $[30,68,69]$, parental grieving evolves over time, and sharing emotional burdens with others throughout the grieving process is extremely helpful in their integration of their grief experience. [37, 70]. Also, helping parents to know that they may grieve differently from each other may help to diminish misunderstandings or reduce additional feelings of distress. [30]

In order to end the existing difficult to locate measures that are suitable for use within palliative care settings, Hudson \& Hayman-White [71] details some topics that can assess the psychosocial characteristics of family caregivers: competence, mastery, self-efficacy, burden, optimism, preparedness, social support, rewards, and mutuality, illustrating that most of the measures analyzed can compound the base of a test that examines the family caregiver experience and test supportive interventions.
Therefore, it is necessary to adopt several measures that could avoid some of the negative consequences of the Palliative Sedation to the relatives of the young patient. Among these measures, there is the necessity to fortify the supportive and care team, in order to diminish guilty and grieve feelings, and to provide courses to the care team that can develop the communication process among them and the family.

\section{Acknowledgements}

We are grateful to the Suicidology Research group -Federal University of Ceará (UFC)/National Council for Scientific and Technological Development (CNPq). We would also like to the Scientific Writing Lab (LABESCI) -Federal University of Cariri (UFCA) and Faculty of Medicine of $A B C$.

\section{References}

1. Fainsinger, R. L., Waller, A., Bercovici, M., Bengtson, K., Landman, W., Hosking, M., \& Nunez-Olarte, J. M., 2000. A multicentre international study of sedation for uncontrolled symptoms in terminally ill patients. Palliative Medicine, 14(4), 257-265.

2. Muller-Busch, H. C., Andres, I., \& Jehser, T., 2003. Sedation in palliative care-a critical analysis of 7 years experience. BMC Palliative Care, 2(1), 2.

3. Stone, P., Phillips, C., Spruyt, O., \& Waight, C., 1997. A comparison of the use of sedatives in a hospital support team and in a hospice. Palliative Medicine, 11(2), 140-144.

4. Sykes, N., \& Thorns, A., 2003. The use of opioids and sedatives at the end of life. The lancet oncology, 4(5), 312-318.

5. Chiu, T. Y., Hu, W. Y., Lue, B. H., Cheng, S. Y., \& Chen, C. Y., 2001. Sedation for refractory symptoms of terminal cancer patients in Taiwan. Journal of pain and symptom management, 21(6), 467-472.

6. Miccinesi, G., Rietjens, J. A., Deliens, L., Paci, E., Bosshard, G., Nilstun, T.,... \& Eureld Consortium., 2006. Continuous deep sedation: physicians' experiences in six European countries. Journal of pain and symptom management, 31(2), 122-129.

7. Bilsen, J., Vander Stichele, R., Broeckaert, B., Mortier, F., \& Deliens, L., 2007. Changes in medical end-of-life practices during the legalization process of euthanasia in Belgium. Social science \& medicine, 65(4), 803-808. 
8. Rietjens, J., van Delden, J., Onwuteaka-Philipsen, B., Buiting, H., van der Maas, P., \& van der Heide, A., 2008. Continuous deep sedation for patients nearing death in the Netherlands: descriptive study. bmj, 336(7648), 810-813.

9. Seale, C., 2009. End-of-life decisions in the UK involving medical practitioners. Palliative Medicine, 23(3), 198-204.

10. Seale, C., 2010. Continuous deep sedation in medical practice: a descriptive study. Journal of pain and symptom management, 39(1), 44-53.

11. Rietjens, J. A., van der Heide, A., Vrakking, A. M., OnwuteakaPhilipsen, B. D., van der Maas, P. J., \& van Der Wal, G., 2004. Physician reports of terminal sedation without hydration or nutrition for patients nearing death in the Netherlands. Annals of internal medicine, 141(3), 178-185.

12. Rietjens, J. A., van Zuylen, L., van Veluw, H., van der Wijk, L., van der Heide, A., \& van der Rijt, C. C., 2008. Palliative sedation in a specialized unit for acute palliative care in a cancer hospital: comparing patients dying with and without palliative sedation. Journal of pain and symptom management, 36(3), 228-234.

13. WHO, 2014. "How many people are in need of palliative care worldwide?" In: Global atlas of palliative care at the end of life.

14. Rietjens, J. A., Hauser, J., Van der Heide, A., \& Emanuel, L., 2007. Having a difficult time leaving: experiences and attitudes of nurses with palliative sedation. Palliative Medicine, 21(7), 643-649.

15. Kiman, R., Wuiloud, A. C., \& Requena, M. L., 2011. End of life care sedation for children. Current opinion in supportive and palliative care, 5(3), 285-290.

16. Hinds, P. S., \& Kelly, K. P., 2010. Helping parents make and survive end of life decisions for their seriously ill child. Nurs Clin N Am,45(3), 465-474.

17. Kars, M. C., Grypdonck, M. H., Beishuizen, A., Meijer van den Bergh, E. M., \& van Delden, J. J., 2010. Factors influencing parental readiness to let their child with cancer die. Pediatric blood \& cancer, 54(7), 1000-1008

18. Rishel, C. J., 2010. Conceptual framework for the study of parental end-of-life decision making in pediatric blood and marrow transplantation. In Oncol Nurs Forum (Vol. 37, No. 2, pp. 184-190). Oncology Nursing Society.

19. Vrakking, A. M., van der Heide, A., Arts, W. F. M., Pieters, R., van der Voort, E., Rietjens, J. A.,... \& van der Wal, G., 2005. Medical end-of-life decisions for children in the Netherlands. Archives of pediatrics \& adolescent medicine, 159(9), 802-809.

20. Pousset, G., Bilsen, J., Cohen, J., Mortier, F., \& Deliens, L., 2011. Continuous deep sedation at the end of life of children in Flanders, Belgium.Journal of pain and symptom management, 41(2), 449-455.

21. Vayne-Bossert, P., \& Zulian, G. B., 2013. Palliative Sedation From the Family Perspective. American Journal of Hospice and Palliative Medicine,30(8), 786-790.
22. Bruinsma, S., Rietjens, J., \& Van Der Heide, A., 2013. Palliative sedation: a focus group study on the experiences of relatives. J Palliat Med, 16(4), 349-355.

23. Lanken, P. N., Terry, P. B., DeLisser, H. M., Fahy, B. F., HansenFlaschen, J., Heffner, J. E.,... \& Yankaskas, J. R., 2008. An official American Thoracic Society clinical policy statement: palliative care for patients with respiratory diseases and critical illnesses. American journal of respiratory and critical care medicine, 177(8), 912-927

24. Burns, J. P., \& Rushton, C. H., 2004. End-of-life care in the pediatric intensive care unit: research review and recommendations. Critical care clinics, 20(3), 467-485.

25. Ganz, F. D., Benbenishty, J., Hersch, M., Fischer, A., Gurman, G., \& Sprung, C. L, 2006. The impact of regional culture on intensive care end of life decision making: an Israeli perspective from the ETHICUS study. Journal of medical ethics, 32(4), 196199.

26. Sprung, C. L., Cohen, S. L., Sjokvist, P., Baras, M., Bulow, H. H., Hovilehto, S.,... \& Ethicus Study Group., 2003. End-of-life practices in European intensive care units: the Ethicus Study. Jama, 290(6), 790-797.

27. Truog, R. D., 2005. Variability in end-of-life care-How much is too much?*.Pediatric Critical Care Medicine, 6(3), 368-369.

28. Van der Heide, A., Deliens, L., Faisst, K., Nilstun, T., Norup, M., Paci, E.,... \& van der Maas, P. J.,2003. End-of-life decisionmaking in six European countries: descriptive study. The Lancet, 362(9381), 345-350.

29. Yaguchi, A., Truog, R. D., Curtis, J. R., Luce, J. M., Levy, M. M., Mélot, C., \& Vincent, J. L. (2005). International differences in end-of-life attitudes in the intensive care unit: results of a survey. Arch Intern Med,165(17), 1970-1975.

30. Hinds, P. S., Oakes, L. L., Hicks, J., \& Anghelescu, D. L., 2005. End-of-life care for children and adolescents. In Seminars in oncology nursing(Vol. 21, No. 1, pp. 53-62). WB Saunders.

31. Thomas, N. D., 2001. The importance of culture throughout all of life and beyond. Holistic Nursing Practice, 15(2), 40-46.

32. Diver, F., Molassiotis, A., \& Weeks, L., 2003. The palliative care needs of ethnic minority patients: staff perspectives. Int J Palliat Nurs, 9(8), 343-351.

33. Nyatanga, B., 2002. Culture, palliative care and multiculturalism. Int J Palliat Nurs, 8(5), 240-246.

34. Browning D: Visiting a foreign culture. IPPC Curriculum, The Initiative for Pediatric Palliative Care. Available at: www. ippcweb.org. (accessed June 8, 2004).

35. Cohen, J., Bilsen, J., Fischer, S., Löfmark, R., Norup, M., Van Der Heide, A.,... \& Deliens, L., 2007. End-of-life decision-making in Belgium, Denmark, Sweden and Switzerland: does place of death make a difference?. Journal of epidemiology and community health, 61(12), 1062-1068. 
36. Dussel, V., Joffe, S., Hilden, J. M., Watterson-Schaeffer, J., Weeks, J. C., \& Wolfe, J., 2010. Considerations about hastening death among parents of children who die of cancer. Arch Pediatr Adolesc Med,164(3), 231-237.

37. Johnson, L. M., Snaman, J. M., Cupit, M. C., \& Baker, J. N., 2014. End-of-Life Care for Hospitalized Children. Pediatric clinics of North America, 61(4), 835-854

38. Stevens M. Paediatric palliative medicine: Care of the dying child and adolescent, family adjustment and support. In: Doyle D, Hanks G, Cherny N, et al, eds. Oxford Textbook of Palliative Medicine (ed 3). Oxford, UK: Oxford University Press: 2003:806821.

39. Contro, N., Larson, J., Scofield, S., Sourkes, B., \& Cohen, H., 2002. Family perspectives on the quality of pediatric palliative care. Arch Pediatr Adolesc Med, 156(1), 14-19.

40. Sykes, N., \& Thorns, A., 2003. Sedative use in the last week of life and the implications for end-of-life decision making. Archives of Internal Medicine,163(3), 341-344.

41. Maltoni, M., Pittureri, C., Scarpi, E., Piccinini, L., Martini, F., Turci, P.,... \& Amadori, D., 2009. Palliative sedation therapy does not hasten death: results from a prospective multicenter study. Annals of Oncology, 20(7), 1163-1169.

42. Mercadante, S., Intravaia, G., Villari, P., Ferrera, P., David, F., \& Casuccio, A., 2009. Controlled sedation for refractory symptoms in dying patients.Journal of pain and symptom management, 37(5), 771-779.

43. Anghelescu, D. L., Oakes, L., \& Hinds, P. S., 2006. Palliative care and pediatrics. Anesthesiology Clinics of North America, 24(1), 145-161.

44. Wolfe, J., Klar, N., Grier, H. E., Duncan, J., Salem-Schatz, S., Emanuel, E. J., \& Weeks, J. C., 2000. Understanding of prognosis among parents of children who died of cancer: impact on treatment goals and integration of palliative care. Jama, 284(19), 2469-2475.

45. De Graves, S., \& Aranda, S. (2002). Exploring documentation of end-of-life care of children with cancer. Int J Palliat Nurs, 8(9), 435-443

46. Meyer, E. C., Burns, J. P., Griffith, J. L., \& Truog, R. D., 2002. Parental perspectives on end-of-life care in the pediatric intensive care unit. Crit Care Med, 30(1), 226-231.

47. Solomon, M. Z., \& Browning, D., 2005. Pediatric palliative care: Relationships matter and so does pain control. Journal of clinical oncology,23(36), 9055-9057.

48. Mack, J. W., Hilden, J. M., Watterson, J., Moore, C., Turner, B., Grier, H. E.,... \& Wolfe, J., 2005. Parent and physician perspectives on quality of care at the end of life in children with cancer. Journal of Clinical Oncology, 23(36), 9155-9161.

49. Van Dooren, S., Van Veluw, H. T., Van Zuylen, L., Rietjens, J. A., Passchier, J., \& Van der Rijt, C. C., 2009. Exploration of concerns of relatives during continuous palliative sedation of their family members with cancer. Journal of pain and symptom management, 38(3), 452-459.
50. Andershed, B., 2006. Relatives in end of life care-part 1: a systematic review of the literature the five last years, January 1999-February 2004.Journal of clinical nursing, 15(9), 11581169.

51. Mercadante, S., 2004. Cancer pain management in children. Palliative medicine, 18(7), 654-662.

52. Bruinsma, S. M., Rietjens, J. A., Seymour, J. E., Anquinet, L., \& van der Heide, A., 2012. The experiences of relatives with the practice of palliative sedation: a systematic review. Journal of pain and symptom management,44(3), 431-445.

.53. Forward, D. R., \& Garlie, N., 2003. Search for new meaning: Adolescent bereavement after the sudden death of a sibling. Can J Sch Psychol, 18(1-2), 23-53.

54. McCulloch, R., \& Collins, J. J., 2006. Pain in children who have life-limiting conditions. Child and adolescent psychiatric clinics of North America, 15(3), issues and practical management. J Palliat Care 1996;12(3):40-5.

55. Kenny, N. P., \& Frager, G., 1996. Refractory symptoms and terminal sedation of children: ethical issues and practical management. J Palliat Care, 12(3), 40.

56. Middleton, W., Raphael, B., Burnett, P., \& Martinek, N., 1998. A longitudinal study comparing bereavement phenomena in recently bereaved spouses, adult children and parents. Aust N Z J Psychiatry, 32(2), 235-241.

57. Kissane, D. W., Bloch, S., Dowe, D. L., Snyder, R. D., Onghena, P., McKenzie, D. P., \& Wallace, C. S., 1996. The Melbourne family grief study, I: Perceptions of family functioning in bereavement. Am J Psychiatry, 153(5), 650-658

58. Kreicbergs, U., Valdimarsdottir, U., ONELOeV, E. R. I. K., Henter, J. I., \& Steineck, G., 2004. Anxiety and depression in parents 4-9 years after the loss of a child owing to a malignancy: a population-based follow-up.Psychological medicine, 34(08), 1431-1441.

59. Harper, M., O'Connor, R. C., \& O'Carroll, R. E., 2011. Increased mortality in parents bereaved in the first year of their child's life. BMJ Support Palliat Care, 1(3), 306-309. 2011.

60. Li, J., Hansen, D., Mortensen, P. B., \& Olsen, J., 2002. Myocardial Infarction in Parents Who Lost a Child A Nationwide Prospective Cohort Study in Denmark. Circulation, 106(13), 1634-1639.

61. Kersting, A., Brähler, E., Glaesmer, H., \& Wagner, B., 2011. Prevalence of complicated grief in a representative populationbased sample. J Affect Disord, 131(1), 339-343.

62. Riley, L. P., \& Coolican, M. B., 1999. Needs of families of organ donors: facing death and life. Crit Care Nurse, 19(2), 53-59.

63. Bartucci, M. R., 1987. Organ donation: a study of the donor family perspective. J Neurosci Nurs, 19(6), 305-309.

64. Coolican, M. B., 1994. Families: facing the sudden death of a loved one.Crit Care Nurs Clin North Am, 6(3), 607-612.

65. Doka KJ, 1995. Children mourning, mourning children. Washington, DC: Hospice Foundation of America. 
66. Robinson, M. R., Thiel, M. M., Backus, M. M., \& Meyer, E. C., 2006. Matters of spirituality at the end of life in the pediatric intensive care unit. Pediatrics, 118(3), 718-729.

67. Kreicbergs, U; Valdimarsdottir, U; Onelov, E; Bjork, O; Steineck, G; Henter, Ji, 2005.Care-related distress: A nationwide survey of parents having lost their child to cancer. J Clin Oncol, 23, 9162 9171.

68. Soricelli, B. A., \& Utech, C. L., 1985. Mourning the death of a child: The family and group process. Soc Work, 30(5), 429434.

69. Rowa-Dewar, N., 2002. Do interventions make a difference to bereaved parents? A systematic review of controlled studies. Int J Palliat Nurs, 8(9), 452-457.

70. Kreicbergs, U. C., Lannen, P., Onelov, E., \& Wolfe, J., 2007. Parental grief after losing a child to cancer: impact of professional and social support on long-term outcomes. J Clin Oncol, 25(22), 3307-3312.

71. Hudson, P. L., \& Hayman-White, K., 2006. Measuring the psychosocial characteristics of family caregivers of palliative care patients: psychometric properties of nine self-report instruments. Journal of pain and symptom management, 31(3), 215-228

\section{Comment on this article:}

\section{f) B in $8+\mathbf{S} P$}
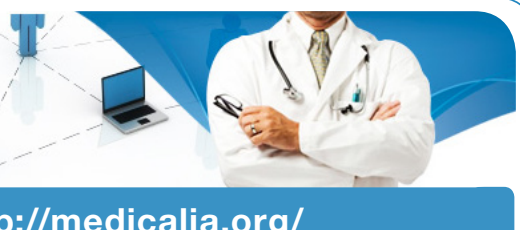

http://medicalia.org/

Where Doctors exchange clinical experiences, review their cases and share clinical knowledge. You can also access lots of medical publications for free. Join Now!

\section{Publish with iMedPub}

http://www.imed.pub

International Archives of Medicine is an open access journal publishing articles encompassing all aspects of medical science and clinical practice. IAM is considered a megajournal with independent sections on all areas of medicine. IAM is a really international journal with authors and board members from all around the world. The journal is widely indexed and classified Q1 in category Medicine. 